\title{
BID TO REDUCE BREAST CANCER DEATHS
}

W omen in NSW aged 50 to 69 years are to be encouraged to have a mammogram every two years, with the aim of reducing breast cancer deaths by up to 30 per cent.

This follows an agreement in principle by Australia's Health Ministers last year that a national mammographic screening program should be implemented.

The outcomes of pilot mammographic screening projects in NSW show that it is possible to match the results of similar overseas trials in which many women's lives were saved.

However, it is important to note that none of the countries which conducted successful trials, such as Sweden and the UK, have fully developed national screening programmes in place ${ }^{1,2}$.

While the results of NSW pilot projects have been encouraging, significant gaps in infrastructure, professional training, planning and consensus remain. Even if NSW had all the resources needed to expand screening throughout the State, an essential ingredient would still be missing. That is the ability to attract at least $70 \%$ of the target population of women. There are practical problems in using electoral rolls, ethical difficulties in using Health Insurance Commission lists, and it would take time to develop strategies to involve women in screening.

The cost effectiveness of the screening programme will be put at risk if the goal of reducing overall deaths from breast cancer is reduced to earlier diagnosis only for the highly motivated.

The NSW Health Minister, Mr Peter Collins, says screening will be expanded progressively from the existing pilot projects. This was the advice to the Minister from the Ministerial Advisory Committee on Mammographic Screening. The advice to the Australian Health Ministers' Advisory Council (AHMAC) from its Breast Cancer Screening Evaluation Steering Committee was that a national programme should be implemented progressively over the next five years to mid-1995.

Calls for an immediate Medicare benefit for screening mammography have lost ground following closer consideration of what is involved in an effective screening programme. Such a move would have led to a haphazard and expensive system lacking organisation, uniform standards and quality assurance, which could have discriminated against lower income women.

Instead, the national programme will be jointly funded by the Commonwealth, States and Territories, with screening and the full assessment process, including surgical biopsy, to be free. The hazards of a market-place approach to mammographic screening were highlighted in a recent American study published in the Annals of Internal Medicine. It revealed almost a four times over-supply of mammography equipment, with the consequent risk of low utilisation rates, higher charges and lower quality standards ${ }^{3}$.

To co-ordinate the development of the Australian programme, a national breast cancer screening advisory committee and a national breast cancer screening co-ordination unit will be set up. NSW and the other States are also setting up screening co-ordination units.

The aim is to develop a system in which a high proportion of women in the target age group will be screened extremely well. This will fulfil the essential criterion of effective screening - a reduction in mortality from breast cancer.

Screening women ad hoc can fail to make much of an impression on breast cancer deaths for a number of reasons:

\begin{tabular}{l|l} 
- early breast cancers may be missed because \\
of technical or interpreting deficiencies; \\
the cancers discovered may already be \\
advanced beyond cure; \\
they may be less aggressive tumours which \\
would have been cured if diagnosed later; \\
the treatment given may be inadequate.
\end{tabular}

Mammographic screening in NSW will spread out from two recently accredited assessment centres the Rachel Forster Hospital in Sydney and the Mater Misericordiae Hospital in Waratah, Newcastle.

These two hospitals are the headquarters of the Central Sydney Area Health Service mammographic screening pilot project and the Hunter Area Health Service pilot project respectively.

These two centres will eventually obtain additional screening units to increase their throughput. The Rachel Forster Centre, which had been operating one mobile unit, commissioned a second mobile unit in December, doubling its screening capacity. The Mater centre expects to have a second mobile unit in service this month.

The Rachel Forster Centre started operation in March 1988 and has so far screened about 16,000 women, though not all of them are among the 43,000 in the target age group for the pilot of $45-70$ years. In some areas, up to 45 per cent of the target population has been screened but, overall, the figure is more like 15 per cent. 


\section{Bid to Reduce Breast Cancer Deaths}

\section{- Confinued from page 44}

During the first 18 months of screening at the Rachel Forster Centre, 51 cancers were diagnosed for a cancer detection rate of seven per 1000 women screened, and about the same rate has been maintained.

The recall rate has fallen from 11.2 per cent to about 6 per cent, reflecting the growing experience of the projects' radiologists. The benign to malignant biopsy ratio has been maintained at about $0.9: 1$, a very satisfactory figure. About 62 per cent of the cancers detected have been impalpable to the examining surgeon and only about $20 \%$ of women diagnosed have had axillary node involvement.

The Mater centre, which has focused on women aged 40 and over, started screening in January 1989 and, by the end of December 1990, had screened 9923.

Screening was impeded by the Newcastle earthquake, but statistics for the 12 months of 1990 show a cancer detection rate of 7.8 per 1000 women screened in the 50-69 age group and 9.9 per 1000 in the 70 -and-over group. In the $40-49$ age group, the detection rate was only 1.6 per 1000 screened.

The recall rate was $13 \%$ and the benign to malignant biopsy ratio was 2.8 to one.

These trials highlight the important role of assessment centres in screening programmes. As is emphasised in the model for the expansion of screening in NSW, the assessment centre is responsible not only for determining who among the 5 - 10 per cent of women with abnormal mammograms actually has breast cancer, but also for maintaining a high quality of service throughout the screening system. It must conduct random reviews of screening films from screening units associated with it to ensure they are technically adequate and that reporting on them is up to standard.

In bringing together the team of specialists required to reach a breast cancer diagnosis without too high a cost in benign biopsies, it must also give confidence to the women with breast cancer and be nonthreatening to the greater number of women who do not have the disease.

Eventually, there will be between $5-10$ assessment centres in NSW, each servicing 3-5 screening units, providing a network covering the whole State.

Screening units may only be developed in association with an assessment centre. They can be in either the public or private sectors. The dedicated equipment which produces high-quality breast X-rays for a minimal radiation dose is largely in private hands in NSW, 70 such machines being in private radiological practices at last count.
Some 50 multidisciplinary groups have considered establishing assessment centres in NSW. The Ministerial Advisory Committee, which called for the expressions of interest, narrowed the field to 22 and forwarded submissions from these applicants to Mr Collins.

One issue remains unresolved - whether women aged 40-49 should be screened. The advice to AHMAC from its screening committee was that screening should be made available and publicised to women aged over 40 years, but that recruitment strategies should target women aged 50-69. The evidence for the effectiveness of screening women aged 40-49 is still limited and indecisive. Until a stronger case can be made out, offering screening to these younger women would seem unwarranted, especially as they would need to present for screening at two-yearly intervals for up to 30 years.

As the programme moves out of trial mode into general screening, aspects of infrastructure and recruitment must be urgently addressed.

The NSW Central Cancer Registry is setting up a screening register to record the results of each woman's screening mammogram, the assessment of screening-detected abnormalities and of any treatment arising from that assessment.

The Cancer Council's Cancer Education Research Project (CERP), within the University of Newcastle, is looking at ways of encouraging women to take part in screening. CERP has been measuring the effect of such strategies as obtaining GPs' co-operation in inviting women to screening, and motivating local communities to encourage women to participate ${ }^{4}$.

Researchers in Sydney University's Department of Public Health have also been looking at methods of attracting women to screening. In a recent paper in Community Health Studies, Associate Professor Les Irwig, Dr Deborah Turnbull and Dr Marilyn McMurchie, reported that 32 per cent of women who received a letter from their GP inviting them to be screened in a pilot project subsequently had a breast X-ray, compared with 7 per cent of women attending the same practice who were not invited ${ }^{5}$.

\section{Elaine Henry \\ NSW Cancer Council}

1. Tabar L, Fagerberg C.JC, Gad A et al. "Reduction in mortality from breast cancer after mass screening with mammography." Lancet 1985, 1:829-32.

2. "Breast cancer screening in Australia: future directions." Australian

Institute of Health: Prevention Program Evaluation Series No 1.

3. Brown ML, Kessler LG and Rueter FG. "Is the supply of mammography 3. Brown ML, Kessler LG and Rueter FG. 'Is the supply of mammography machines outs
$113 ; 7547-552$.

4. Sanson-Fisher RW, Webb GR and Reid ALA. "The role of the medical

4. Sanson-Fisher RW, Webb GR and Reid ALA." The role of the medical
practitioner as an agent of disease prevention." Better Health Commisssion, practitioner as an agent of disease prevention." Better Health Commisssion, Government Printing Service, 1986

5. Irwig L, Turnbull D, McMurchie M. "A randomised trial of general practitioners - written invitations to encourage attendance at screening mammography." Community Health Studies, XIV No 4, 1990;357-363. 